\title{
Intra-Articular Injection of Bone Marrow-Derived Mesenchymal Stem Cells Leading to Better Clinical Outcomes without Difference in MRI Outcomes from Baseline in Patients with Knee Osteoarthritis
}

\author{
Young-Soo Shin, $\mathrm{MD}, \mathrm{PhD}^{1, \star}$, Jung-Ro Yoon, $\mathrm{MD}, \mathrm{PhD}^{1, \star}$, Hee-Sun $\mathrm{Kim}, \mathrm{RN}, \mathrm{PhD}^{2}$, and \\ Seon-Heui Lee, RN, $\mathrm{PhD}^{3}$ \\ ${ }^{1}$ Department of Orthopedic Surgery, Veterans Health Service Medical Center, Seoul; ${ }^{2}$ Chonbuk Research Institute of Nursing Science, College of Nursing, Chonbuk \\ National University, Jeonju; ${ }^{3}$ Department of Nursing Science, College of Nursing, Gachon University, Incheon, Korea
}

\begin{abstract}
Purpose: Bone marrow (BM) is frequently used as a source of mesenchymal stem cells (MSCs) because they have a high potential for differentiation. However, it is unclear whether BM-derived MSCs lead to better clinical and magnetic resonance imaging (MRI) outcomes postoperatively.

Materials and Methods: This meta-analysis compared the clinical and MRI outcomes in patients with knee osteoarthritis (OA) treated with BMderived MSCs. Eight studies comparing the clinical and MRI outcomes assessed with various measurement tools in patients with knee OA treated with BM-derived MSCs were included.

Results: The range of motion (95\% confidence interval [CI], -13.05 to $4.24 ; \mathrm{p}=0.32$ ) and MRI outcomes (95\% CI, -0.16 to 1.40 ; $\mathrm{p}=0.12)$ did not differ significantly between the baseline and final follow-up. In contrast, pain (95\% CI, 0.89 to 1.87 ; $\mathrm{p}<0.001)$ and functional outcomes (95\% CI, 0.70 to 2.07 ; $\mathrm{p}<0.001$ ) were significantly improved at the final follow-up when compared to the baseline.

Conclusions: This meta-analysis found no significant difference in the tested range of motion and MRI outcomes between the baseline and the final follow-up in patients treated with BM-derived MSCs, whereas significant functional improvement and pain relief were noted when compared with the baseline. Thus, BM-derived MSCs appear to be a viable alternative for patients with knee OA, although long-term and high-quality randomized controlled trials are needed to confirm the clinical benefits.
\end{abstract}

Keywords: Knee, Osteoarthritis, Bone marrow, Mesenchymal stem cells, Meta-analysis

\section{Introduction}

Osteoarthritis $(\mathrm{OA})$ is a progressively debilitating condition that causes cartilage erosion of the involved joint with pain and func-

Received December 19, 2017; Revised February 6, 2018;

Accepted April 24, 2018

Correspondence to: Seon-Heui Lee, RN, PhD

Department of Nursing Science, College of Nursing, Gachon University, 21 Namdong-daero, 774 beon-gil, Namdong-gu, Incheon 21565, Korea Tel: +82-32-820-4230, Fax: +82-32-820-4231

E-mail: sunarea87@gachon.ac.kr

*These authors contributed equally to this study.

This is an Open Access article distributed under the terms of the Creative Commons Attribution Non-Commercial License (http://creativecommons.org/licenses/by-nc/4.0/) which permits unrestricted non-commercial use, distribution, and reproduction in any medium, provided the original work is properly cited. tional impairment. Traditional methods to regenerate defects of articular cartilage include microfracture, multiple perforations, abrasions and mosaicplasty, the results of which are not satisfactory ${ }^{1,2}$. Autologous chondrocyte implantation (ACI) could be one method to regenerate an articular cartilage defect. However, ACI is not applicable to articular cartilage defects in OA because chondrocytes from patients suffering from OA have totally different biological properties ${ }^{3)}$. Additionally, for large articular cartilage defects in patients with OA, an alternative cell source should be found. As an alternative, mesenchymal stem cells (MSCs) can be used to regenerative articular cartilage defects ${ }^{4}$. MSCs can be isolated from a variety of sources, such as bone marrow (BM), adipose tissue, umbilical cord, amniotic fluid, dental pulp, synovial tissue, peripheral blood and skeletal muscles. It has been reported that the BM-derived MSCs contain progenitor cells of 
some mesenchymal tissues, such as cartilage and other tissues ${ }^{5}$. Furthermore, BM is frequently used as a source for MSCs because they are relatively easy to isolate and they have a high potential for differentiation, even though it needs amount increases over several weeks in culture conditions for effective cellular dosage $^{6}$. Although there have been many studies on adipose-derived MSCs or adipose-derived stromal vascular fraction ${ }^{7-10}$, few have assessed BM-derived MSCs and the results have been inconclusive. Previous studies have conducted a systematic review of the MSCs for the treatment of cartilage lesions ${ }^{11,12)}$; however, evidence is insufficient due to the different location of cartilage defect, different cell sources, different etiology, and different MSC dosage. Few direct comparisons of clinical scores on knee outcome scales and magnetic resonance imaging (MRI) outcomes between the baseline and final follow-up have been conducted in patients with knee OA treated with BM-derived MSCs. In addition, no metaanalyses on this subject have been published.

This meta-analysis was performed to assess clinical and MRI outcomes after surgery in patients with knee OA treated with BM-derived MSCs. It was hypothesized that BM-derived MSCs would lead to better clinical outcomes and MRI outcomes on final follow-up in these patients.

\section{Materials and Methods}

\section{Data and Literature Sources}

This study followed the Cochrane Review Methods. Multiple comprehensive databases, including MEDLINE (January 1, 1976 to September 30,2017), EMBASE (January 1, 1985 to September 30, 2017), and the Cochrane Library (January 1, 1987 to September 30, 2017) were searched for studies of patients with knee OA treated with BM-derived MSCs which used the following assessments to compare clinical outcome: visual analog scale (VAS) for pain, Western Ontario McMaster Universities Arthritis Index (WOMAC), Lysholm score, Hospital for Special Surgery (HSS) score and range of motion (ROM). Selected studies also compared MRI outcomes using the whole-organ magnetic resonance imaging score (WORMS) and poor cartilage index (PCI). There was no language restriction, and filters of any kind were not applied for the strategy. The following keywords and their comprehensive combination and pertinent Medical Subject Headings (MeSH) were used to select the relevant articles: 'mesenchymal stem cells' OR 'mononuclear cells' OR 'bone marrow-derived mesenchymal stem cell' OR 'bone marrow stromal cells' OR 'muscular skeletal disease' OR 'osteoarthritis'.

After the initial electronic search, relevant articles and their bib- liographies were searched manually.

\section{Study Selection}

Based on the title and abstract, two reviewers independently selected the relevant studies for full review. The full text copy of each article was reviewed if the abstract did not provide enough data to make a decision. Studies were included in the metaanalysis if they (1) assessed clinical outcomes, as determined by VAS for pain, WOMAC, Lysholm score, HSS score and ROM between the baseline and final follow-up, and MRI outcomes, as determined by WORMS and PCI between the baseline and final follow-up; (2) reported direct comparisons of surgical outcomes in patients with knee OA treated with intra-articular injections of BM-derived MSCs; (3) included data on at least one of the following 7 parameters: VAS for pain, WOMAC, Lysholm score, HSS score, ROM, WORMS and PCI. For the overall functional outcome measure, we combined comparable scores from different functional outcome tools when these tools scored disability: the higher the score, the greater the disability. Using the same method, we combined comparable scores of postoperative pain: the higher the score, the greater the pain. For WORMS, we recorded total WORMS score as assessed by cartilage thickness, signal intensity, and subchondral bone alteration and volume. The higher score values indicate more damage ${ }^{13)}$. PCI was evaluated using the mean T2 relaxation values sampled in 88 well-defined regions of interest: values at 100 present the worst possible PCI, and those at 5 or below are considered healthy ${ }^{14}$; (4) fully reported the number of patients in each group (baseline and final follow-up groups) and the means and standard deviations for the 7 parameters; and (5) used adequate statistical methods to compare these parameters between groups. Studies were excluded if they (1) were not original articles; (2) were pre-clinical studies; (3) had missing or inadequate outcome data, such as standard deviations or ranges of values; and (4) used open surgery as the delivery method.

\section{Data Extraction and Methodological Quality Assessment}

Two reviewers independently recorded data from each study using a predefined data extraction form and resolved any differences by discussion. Variables recorded included those associated with surgical outcomes, such as VAS for pain, WOMAC, Lysholm score, HSS score, ROM, WORMS and PCI. Sample size and the mean and standard deviation of surgical outcomes in each group were also recorded. If these variables were not included in the articles, the standardized mean difference (SMD) was calculated from the p-value and sample size. 
Two reviewers independently assessed the methodological quality of the studies using interrupted time series analyses, as recommended by the Cochrane Effective Practical and Organisation of Care Group. Each study was judged based on seven standard criteria to detect whether the intervention has an effect significantly greater than the underlying secular trend. Any unresolved disagreements between reviewers were resolved by consensus or by consultation with a third investigator.

\section{Data Synthesis and Analysis}

The main outcomes of the meta-analysis were the SMD for overall clinical outcomes and MRI outcomes at the final followup compared to the baseline values due to use of several different measurement tools, including VAS for pain, WOMAC, Lysholm score, HSS score, ROM, WORMS and PCI. For all comparisons, SMD and 95\% confidence interval (CI) were calculated for continuous outcomes. Heterogeneity was determined by estimating the proportion of between-study inconsistencies due to actual differences between studies, rather than differences due to random error or chance, using the $\mathrm{I}^{2}$ statistic, with values of $25 \%$, $50 \%$, and $75 \%$ considered low, moderate, and high heterogeneity, respectively. All statistical analyses were performed with RevMan ver. 5.3 (The Cochrane Collaboration, Copenhagen, Denmark). The risks of bias (low, high, or unclear) were independently assessed by two investigators. Subgroup analyses based on differ- ences in the length of follow-up time were performed for pain scores in an attempt to explore a potential source of heterogeneity. As a result, two subgroups were created: follow-up more than 3 years and follow-up less than 3 years for pain scores. In addition, sensitivity analysis was conducted by excluding one of the eligible studies at a time; two studies with additional surgical procedures, such as cartilage treatment and osteotomy were included ${ }^{15,16}$. Pooling of data was feasible for only two outcomes of interest, i.e., pain and function scores.

\section{Resullts}

\section{Identification of Studies}

Details on study identification, inclusion, and exclusion are summarized in Fig. 1. An electronic search yielded 270 studies in PubMed (MEDLINE), 309 in EMBASE and 3 in the Cochrane Library. Two additional publications were identified through manual searching. After removing 152 duplicates, 432 studies remained; of these, 16 were excluded based on the abstract and fulltext article review, and an additional eight studies were excluded because they had unusable information or made inappropriate group comparisons. This eventually resulted in 8 studies that were included in the meta-analysis ${ }^{15-22)}$.

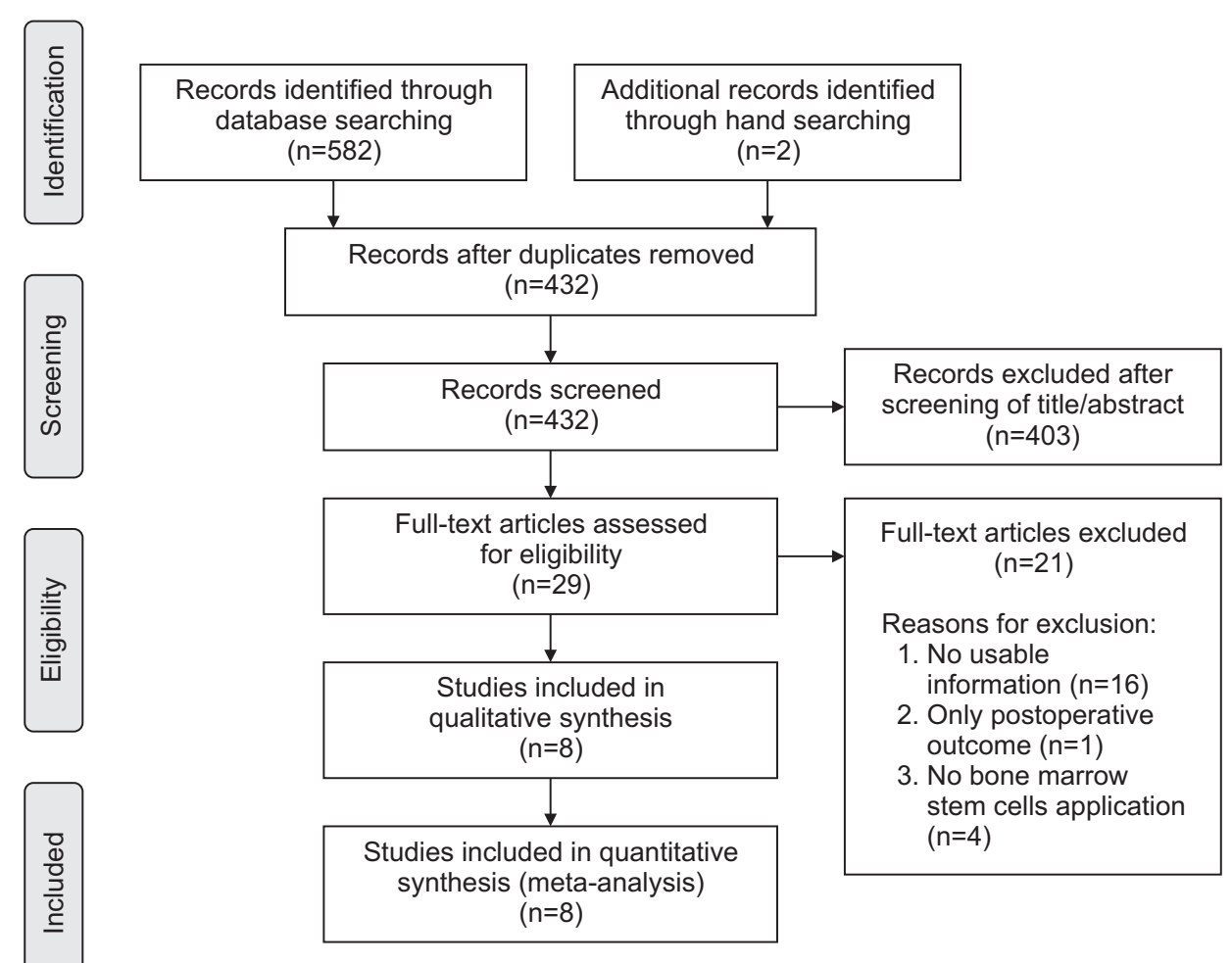

Fig. 1. Preferred Reporting Items for Systematic Reviews and Meta-Analyses (PRISMA) flow diagram of literature selection. 


\section{Study Characteristics and Patient Populations}

The 8 studies we examined included 161 patients who underwent surgical treatment for knee OA with BM-derived MSCs. Five studies ( 5 randomized controlled trials [RCTs]) compared prospectively measured parameters, whereas the other three studies compared parameters measured by retrospective chart review. Seven studies reported pain score, six reported function score, four reported MRI score, and two reported ROM (Table 1).

\section{Quality and Publication Bias of the Included Studies}

The quality of the 8 studies included in the meta-analysis is summarized in Table 2. Publication bias could not be assessed in these trials. Tests for funnel plot asymmetry are typically per- formed only when at least 10 studies are included in the metaanalysis. The meta-analysis included only 8 studies, and tests for asymmetry were not performed because these tests would not be able to differentiate asymmetry from chance.

\section{Clinical Outcomes}

Of the 8 studies, 7 compared pain score and included 133 patients assessed at the baseline and 133 at the final follow-up. The standardized mean was 1.38 points lower at the final followup than at the baseline, and was significantly different between groups (95\% CI, 0.89 to 1.87 points; $\mathrm{p}<0.001 ; \mathrm{I}^{2}=62 \%$ ) (Fig. 2). Two studies were assigned to the follow-up more than 3 years and five studies to the follow-up less than 3 years. The standard-

Table 1. Summary of Study Characteristics

\begin{tabular}{|c|c|c|c|c|c|c|c|c|c|c|c|}
\hline Study & Year & $\begin{array}{l}\text { Study } \\
\text { type }\end{array}$ & $\begin{array}{c}\text { No. of } \\
\text { patients } \\
(\mathrm{M} / \mathrm{F})\end{array}$ & $\begin{array}{c}\text { Mean } \\
\text { age } \\
(\mathrm{yr})\end{array}$ & $\begin{array}{c}\text { BMI } \\
\left(\mathrm{kg} / \mathrm{m}^{2}\right)\end{array}$ & $\begin{array}{c}\text { Mean } \\
\text { final F/U } \\
\quad(\mathrm{mo})\end{array}$ & $\begin{array}{c}\text { Cell } \\
\text { number }\end{array}$ & $\begin{array}{l}\text { Amount } \\
(\mathrm{mL})\end{array}$ & $\begin{array}{l}\text { Delivery } \\
\text { method }\end{array}$ & $\begin{array}{c}\text { Concomitant } \\
\text { procedure }\end{array}$ & $\begin{array}{l}\text { Measured } \\
\text { parameter }\end{array}$ \\
\hline Davatchi et al. ${ }^{17)}$ & 2016 & OCS & $4(2 / 2)$ & 57.8 & 31.4 & 60 & $8-9 \times 10^{6}$ & 30 & IA injection & No & PS, ROM \\
\hline $\begin{array}{l}\text { Emadedin } \\
\text { et al. }^{18)}\end{array}$ & 2015 & OCS & $6(0 / 6)$ & 54.5 & NA & 60 & $5 \times 10^{5}$ & 50 & IA injection & No & PS, FS \\
\hline Gupta et al. ${ }^{19)}$ & 2016 & RCT & $40(12 / 28)$ & 56.1 & 28.1 & 12 & $25-150 \times 10^{6}$ & NA & IA injection & No & PS, FS, MRIS \\
\hline $\begin{array}{l}\text { Lamo-Espinosa } \\
\text { et al. }^{20)}\end{array}$ & 2016 & RCT & $20(12 / 8)$ & 61.9 & 27.8 & 12 & $10-100 \times 10^{6}$ & NA & IA injection & No & $\begin{array}{l}\text { PS, FS, ROM, } \\
\text { MRIS }\end{array}$ \\
\hline Orozco et al. ${ }^{21)}$ & 2014 & OCS & $12(6 / 6)$ & 49 & NA & 12 & $40 \times 10^{6}$ & 86 & IA injection & No & PS, FS, MRIS \\
\hline $\begin{array}{l}\text { Vangsness } \\
\text { et al. }^{16)}\end{array}$ & 2014 & RCT & $36(28 / 11)$ & 46 & NA & 24 & $50-150 \times 10^{6}$ & NA & IA injection & Meniscectomy & PS, FS \\
\hline Vega et al. ${ }^{22)}$ & 2015 & RCT & $15(6 / 9)$ & 52.6 & NA & 12 & $40 \times 10^{6}$ & 103 & IA injection & No & PS, MRIS \\
\hline Wong et al. ${ }^{15)}$ & 2013 & RCT & $28(15 / 13)$ & 53 & 23.8 & 24.8 & $1.46 \times 10^{7}$ & 49 & IA injection & $\begin{array}{l}\mathrm{HTO}+ \\
\text { microfracture }\end{array}$ & FS \\
\hline
\end{tabular}

BMI: bone mineral density, F/U: follow-up, OCS: observational case series, IA: intra-articular, PS: pain score, ROM: range of motion, NA: not available, FS: function score, RCT: randomized controlled trial, MRIS: magnetic resonance imaging score, HTO: high tibial osteotomy.

Table 2. Risk of Bias Summary: Our Judgment on the Risk for Each Bias Item for Each Included Study

\begin{tabular}{|c|c|c|c|c|c|c|c|c|}
\hline Study & Year & $\begin{array}{c}\text { Intervention } \\
\text { independent } \\
\text { of other } \\
\text { change }\end{array}$ & $\begin{array}{l}\text { Shape of the } \\
\text { intervention } \\
\text { effect } \\
\text { prespecified }\end{array}$ & $\begin{array}{l}\text { Intervention } \\
\text { unlikely to } \\
\text { affect data } \\
\text { collection }\end{array}$ & $\begin{array}{c}\text { Knowledge of } \\
\text { the allocated } \\
\text { interventions } \\
\text { adequately prevented }\end{array}$ & $\begin{array}{c}\text { Incomplete } \\
\text { outcome data } \\
\text { adequately } \\
\text { addressed }\end{array}$ & $\begin{array}{l}\text { Study free } \\
\text { from selective } \\
\text { outcome } \\
\text { reporting }\end{array}$ & $\begin{array}{l}\text { Study free } \\
\text { from other } \\
\text { risks of bias }\end{array}$ \\
\hline Davatchi et al. ${ }^{17)}$ & 2016 & - & - & - & Unclear risk of bias & - & - & + \\
\hline Emadedin et al. ${ }^{18)}$ & 2015 & - & - & - & Unclear risk of bias & - & - & + \\
\hline Gupta et al. ${ }^{19)}$ & 2016 & - & - & - & Unclear risk of bias & - & - & + \\
\hline Lamo-Espinosa et al. ${ }^{20)}$ & 2016 & - & - & - & Unclear risk of bias & + & - & + \\
\hline Orozco et al. ${ }^{21)}$ & 2014 & - & - & - & Unclear risk of bias & - & - & + \\
\hline Vangsness et al. ${ }^{16)}$ & 2014 & - & - & - & Unclear risk of bias & + & - & + \\
\hline Vega et al. ${ }^{22)}$ & 2015 & - & - & - & Unclear risk of bias & - & - & + \\
\hline Wong et al. ${ }^{15)}$ & 2013 & - & - & - & Unclear risk of bias & - & - & + \\
\hline
\end{tabular}

-: low risk of bias, + : high risk of bias. 


\begin{tabular}{|c|c|c|c|c|c|c|c|c|c|c|}
\hline Study or subgroup & \multicolumn{3}{|c|}{ Preoperative } & \multicolumn{3}{|c|}{ Postoperative } & $\begin{array}{l}\text { Weight } \\
(\%)\end{array}$ & $\begin{array}{l}\text { Std. mean difference } \\
\text { IV, random, } 95 \% \mathrm{Cl}\end{array}$ & \multicolumn{2}{|c|}{$\begin{array}{l}\text { Std. mean difference } \\
\text { IV, random, } 95 \% \mathrm{Cl}\end{array}$} \\
\hline \multicolumn{11}{|l|}{ 1.1.1 Follow-up (>3 years) } \\
\hline Davatchi et al. 2016 & 86.25 & 4.79 & 4 & 56.25 & 27.8 & 4 & 6.6 & $1.31[-0.34,2.96]$ & & \\
\hline Emadendin et al. 2015 & 80 & 17 & 6 & 57 & 13 & 6 & 9.0 & $1.40[0.08,2.73]$ & & \\
\hline Subtotal $(95 \% \mathrm{Cl})$ & & & 10 & & & 10 & 15.5 & $1.37[0.33,2.40]$ & & \\
\hline \multicolumn{11}{|c|}{ Heterogeneity: $\operatorname{Tau}^{2}=0.00 ; \mathrm{Chi}^{2}=0.01, \mathrm{df}=1(p=0.93) ; I^{2}=0 \%$} \\
\hline \multicolumn{11}{|c|}{ Test for overall effect: $Z=2.59(p=0.010)$} \\
\hline \multicolumn{11}{|l|}{ 1.1.2 Follow-up (<3 years) } \\
\hline Gupta et al. 2016 & 59.65 & 22.27 & 40 & 37.22 & 24.69 & 40 & 21.0 & $0.94[0.48,1.41]$ & & - - \\
\hline Lamo-Espinosa et al. 2016 & 60 & 18 & 20 & 18 & 9 & 20 & 13.6 & $2.89[1.98,3.80]$ & & \\
\hline Orozco et al. 2014 & 46.9 & 26 & 12 & 15.4 & 13.2 & 12 & 13.5 & $1.48[0.55,2.40]$ & & \\
\hline Vangsness et al. 2014 & 50 & 25.1 & 36 & 23.9 & 16.8 & 36 & 20.3 & $1.21[0.70,1.71]$ & & \\
\hline Vega et al. 2015 & 54 & 27.11 & 15 & 33 & 23.24 & 15 & 16.1 & $0.81[0.06,1.56]$ & & \\
\hline Subtotal $(95 \% \mathrm{Cl})$ & & & 123 & & & 123 & 84.5 & $1.40[0.80,1.99]$ & & \\
\hline \multicolumn{11}{|c|}{ Heterogeneity: $\operatorname{Tau}^{2}=0.33 ; \mathrm{Chi}^{2}=15.74, \mathrm{df}=4(\mathrm{p}=0.003) ; \mathrm{I}^{2}=75 \%$} \\
\hline \multicolumn{11}{|c|}{ Test for overall effect: $Z=4.62(p<0.001)$} \\
\hline Total $(95 \% \mathrm{Cl})$ & & & 133 & & & 133 & 100.0 & $1.38[0.89,1.87]$ & & \\
\hline \multicolumn{11}{|c|}{ Heterogeneity: Tau $^{2}=0.24 ; \mathrm{Chi}^{2}=15.80, \mathrm{df}=6(\mathrm{p}=0.01) ; I^{2}=62 \%$} \\
\hline \multicolumn{7}{|c|}{ Test for overall effect: $Z=5.51(p<0.001)$} & & -4 & -2 & 0 \\
\hline \multicolumn{7}{|c|}{ Test for subgroup differences: $\mathrm{Chi}^{2}=0.00, \mathrm{df}=1(\mathrm{p}=0.96) ; \mathrm{I}^{2}=0 \%$} & & & [prec & ] Favou \\
\hline
\end{tabular}

Fig. 2. Results of aggregate analysis for comparison of pain score between at baseline and at final follow-up. Std.: standardized, SD: standard deviation, CI: confidence interval.

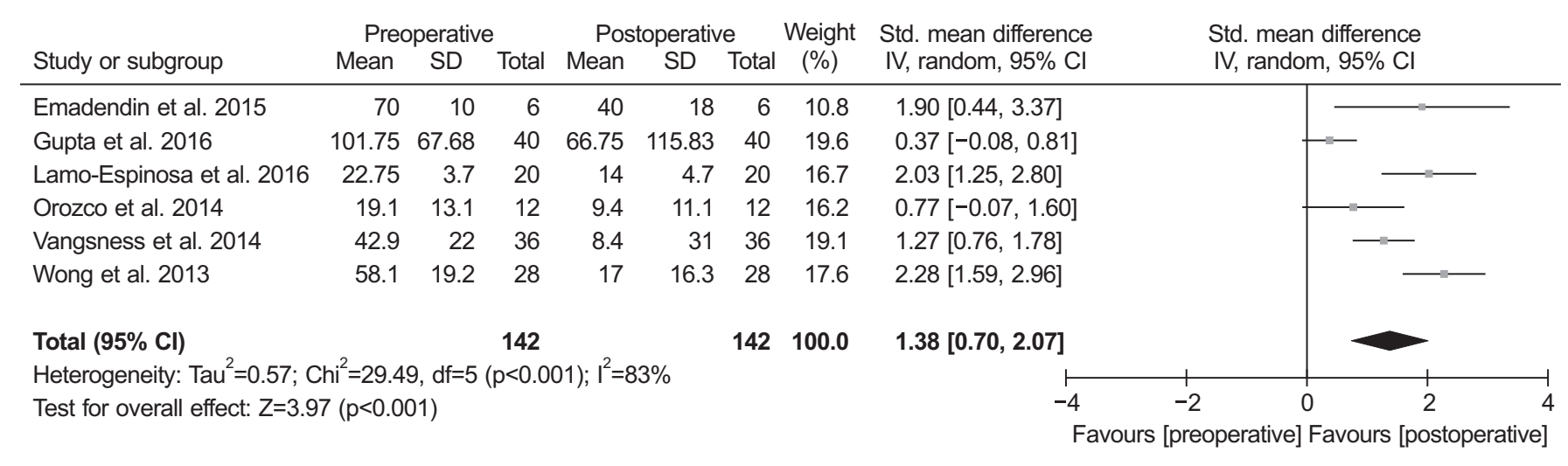

Fig. 3. Results of aggregate analysis for comparison of function score between at baseline and at final follow-up. Std.: standardized, SD: standard deviation, $\mathrm{CI}$ : confidence interval.

ized mean in the more than 3 years of follow-up subgroup was 1.37 points lower at the final follow-up than at the baseline, and this difference was significant (95\% CI, 0.33 to 2.40 points; $\mathrm{p}=0.01 ; \mathrm{I}^{2}=0 \%$ ) (Fig. 2). Likewise, the value in the less than 3 years of follow-up subgroup was 1.40 points lower at the final follow-up than at the baseline, and this difference was significant ( $95 \%$ CI, 0.80 to 1.99 points; $\mathrm{p}<0.001 ; \mathrm{I}^{2}=62 \%$ ) (Fig. 2). Six studies, including 142 patients assessed at the baseline and 142 at the final follow-up, reported function score. The standardized mean was 1.38 points lower at the final follow-up than at the baseline, and there was significant difference between groups (95\% CI, 0.70 to 2.07 points; $\mathrm{p}<0.001 ; \mathrm{I}^{2}=83 \%$ ) (Fig. 3). The results of sensitivity analysis were not materially differentiated from those of the original analysis (Table 3).

\section{ROM and MRI Outcomes}

Of the 8 studies, two compared ROM and included 24 patients assessed at the baseline and 24 at the final follow-up. The standardized mean in ROM was $-4.41^{\circ}$ lower at the baseline than at the final follow-up ( $95 \% \mathrm{CI},-13.05^{\circ}$ to $4.24^{\circ} ; \mathrm{p}=0.32 ; \mathrm{I}^{2}=98 \%$ ) (Fig. 4). Of the 8 studies, 4 compared MRI outcome and included 87 patients assessed with MRI at the baseline and 87 at the final 
Table 3. Sensitivity Analysis

\begin{tabular}{|c|c|c|c|c|c|c|c|c|c|c|c|}
\hline \multirow{2}{*}{ Study } & \multirow{2}{*}{ Year } & \multirow{2}{*}{ Parameter } & \multicolumn{4}{|c|}{ Before exclusion } & \multicolumn{4}{|c|}{ After exclusion } & \multirow{2}{*}{$\begin{array}{c}\text { Statistical } \\
\text { significance }\end{array}$} \\
\hline & & & $\mathrm{MD}$ & $95 \% \mathrm{CI}$ & z-value & $\mathrm{p}$-value & $\mathrm{MD}$ & $95 \% \mathrm{CI}$ & z-value & $\mathrm{p}$-value & \\
\hline $\begin{array}{l}\text { Vangsness } \\
\text { et al. }{ }^{16)}\end{array}$ & 2014 & Pain score & 1.38 & 0.89 to 1.87 & 5.51 & $<0.001$ & 1.44 & 0.80 to 2.09 & 4.38 & $<0.001$ & No difference \\
\hline Wong et al. ${ }^{15)}$ & 2013 & Function score & 1.38 & 0.70 to 2.07 & 3.97 & $<0.001$ & 1.17 & 0.52 to 1.83 & 3.52 & $<0.001$ & No difference \\
\hline
\end{tabular}

MD: mean difference, CI: confidence interval.

\begin{tabular}{|c|c|c|c|c|c|c|c|c|c|c|}
\hline \multirow[b]{2}{*}{ Study or subgroup } & \multicolumn{3}{|c|}{ Preoperative } & \multicolumn{3}{|c|}{ Postoperative } & \multirow{2}{*}{$\begin{array}{l}\text { Weight } \\
(\%)\end{array}$} & \multirow{2}{*}{$\begin{array}{l}\text { Std. mean difference } \\
\text { IV, random, } 95 \% \mathrm{Cl}\end{array}$} & \multirow{2}{*}{$\begin{array}{l}\text { Std. mean difference } \\
\text { IV, random, } 95 \% \mathrm{Cl}\end{array}$} & \\
\hline & Mean & SD & Total & Mean & SD & Total & & & & \\
\hline Davatchi et al. 2016 & 106.25 & 33.26 & 4 & 107.5 & 31.75 & 4 & 50.4 & $-0.03[-1.42,1.35]$ & & \\
\hline Lamo-Espinosa et al. 2016 & 109 & 1 & 20 & 118.5 & 1.1 & 20 & 49.6 & $-8.86[-10.99,-6.72]$ & & \\
\hline Total $(95 \% \mathrm{Cl})$ & & & 24 & & & 24 & 100.0 & $-4.41[-13.05,4.24]$ & & \\
\hline \multicolumn{10}{|c|}{ Heterogeneity: $\operatorname{Tau}^{2}=38.09 ; \mathrm{Chi}^{2}=46.13, \mathrm{df}=1(\mathrm{p}<0.001) ; \mathrm{I}^{2}=98 \%$} & \\
\hline \multicolumn{7}{|c|}{ Test for overall effect: $Z=1.00(p=0.32)$} & & -50 & -25 & 50 \\
\hline
\end{tabular}

Fig. 4. Results of aggregate analysis for comparison of range of motion (ROM) between at baseline and at final follow-up. Std.: standardized, SD: standard deviation, CI: confidence interval.

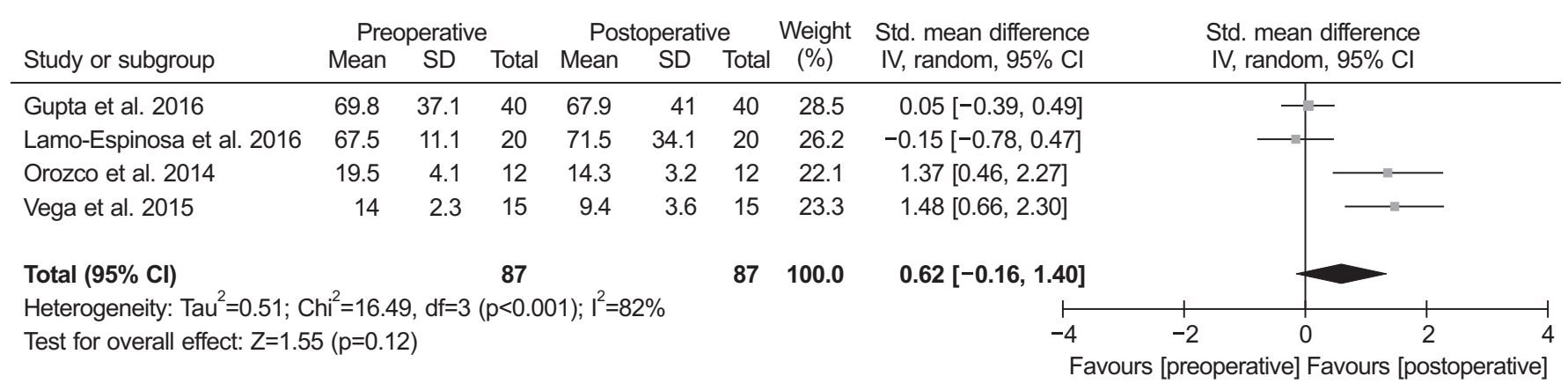

Fig. 5. Results of aggregate analysis for comparison of MRI outcome between at baseline and at final follow-up. Std.: standardized, SD: standard deviation, CI: confidence interval.

follow-up. The standardized mean in MRI outcome was 0.62 lower at the final follow-up than at the baseline (95\% CI, -0.16 to $1.40 ; \mathrm{p}=0.12 ; \mathrm{I}^{2}=82 \%$ ) (Fig. 5).

\section{Discussion}

The main findings of the current meta-analysis verified that there were no significant differences in the tested ROM and MRI outcomes when compared to the baseline values in patients treated with BM-derived MSCs, whereas significant functional improvement and pain relief from the baseline were observed.

BM stromal cells (BMSCs) can be used as a cell suspension expanded by culture or just as BM concentrate (BMC). There are some differences between these two procedures. Expanded BMSCs require two-step procedures in addition to legal approval for the clinical application and cost disadvantages. In contrast, BMC contains a mixture of different red blood cells, platelets, and leukocytes ${ }^{23)}$. The adult MSC fraction is present in the leukocytes of the marrow, and their number is very limited compared to cultured MSCs. The marrow MSC and MSC precursors are extremely rare under normal conditions in human marrow before culture $^{24)}$. Some authors suggested that for favorable chondrogenesis, the optimal count of MSCs per $\mathrm{cm}^{3}$ is an important factor ${ }^{25)}$. However, there is no study of comparison between BMSC and BMC treatment. The treatment using expanded BMSCs might be difficult to manage from a legal point of view because it might be considered as a pharmacological agent administration. In Korea, unlike BMC, expanded BMSCs need additional approval by the Korean Food and Drug Administration for the treatment of OA. In spite of the complicated procedure, whether the in vitro expan- 
sion influenced the effect of clinical application of MSCs was still unclear. For the fate of MSCs in vivo, current studies are not conclusive on this question: some have suggested MSCs differentiate and survive in vivo up to 6 months, while others suggest MSCs have a chondroinductive role of stimulating cartilage regeneration through trophic factors while slowly disappearing from the culture $^{26)}$. BM-derived MSCs administered into knee have adhered to the surface of a damaged tissue, have differentiated into chondrocyte, and have expressed appropriate extracellular matrix protein, resulting in anatomic restoration on the damaged tissue with a significant relief of pain and disability ${ }^{16,21,22}$. Our metaanalysis found that MRI outcomes did not show a significant difference from baseline despite the pain and functional advantages of injected BM-derived MSCs. The similar results for the MRI outcomes were likely due to the cell dose injected into the knee and culture conditions, suggesting that an optimal cell density and purity could affect the cell expansion. According to the animal study of Agung et al. ${ }^{27}$, the ideal number of MSCs that are needed for the regeneration of cartilage is known to be $1 \times 10^{7}$, and a few clinical studies report that $1 \times 10^{7}$ or more adult stem cells are ideal. Minimal criteria to define expanded multipotent human MSCs, as defined by the International Society for Cellular Therapy, include that they must be plastic-adherent when maintained in standard culture conditions, express CD105, CD73 and CD90, and lack expression of CD45, CD34, CD14 or CD11ß, CD79 $a$ or CD19 and HLA-DR surface molecules, and they must be capable of differentiating into osteoblasts, adipocytes and chondroblasts in vitro ${ }^{28)}$. Among our included articles, 6 studies $^{16,19-22)}$ met the ideal number of MSCs, 2 studies $^{17,18)}$ used less than $1 \times 10^{7}$ MSCs. For MSC characterization, 2 studies ${ }^{16,21)}$ did not describe the expression of $\mathrm{CD}$. This could result in poor MRI outcomes than expected. In our meta-analysis, the tested ROM did not demonstrate any significant difference after BM-derived MSCs administration. These results may also be partly explained by small patient samples, which can lead to reduced statistical power and less precision. Thus, the ROM outcomes of the current meta-analysis could not be extended to all knee OA patients and further investigation through a future high volume study is necessary.

This study had several limitations. Of the 8 studies, 3 were observational comparison studies, which are prone to both systematic and random errors, suggesting some inherent heterogeneity due to uncontrolled bias. In addition, the heterogeneity of the included studies could be explained by slight differences in other factors affecting clinical outcomes, including the use of a wide variety of cell dose and cell processing methods ${ }^{29)}$ as well as vari- ability in functional and pain scores.

\section{Conclusions}

This meta-analysis found no significant differences in the tested ROM and MRI outcomes in patients treated with BM-derived MSCs. On the other hand, they showed significant functional improvement and pain relief when compared with the baseline. Thus, BM-derived MSCs appear to be a viable alternative for patients with knee OA, although long-term and high-quality RCTs are needed to confirm the clinical benefits.

\section{Conflict of Interest}

No potential conflict of interest relevant to this article was reported.

\section{References}

1. Hunziker EB. Articular cartilage repair: basic science and clinical progress: a review of the current status and prospects. Osteoarthritis Cartilage. 2002;10:432-63.

2. Steadman JR, Rodkey WG, Rodrigo JJ. Microfracture: surgical technique and rehabilitation to treat chondral defects. Clin Orthop Relat Res. 2001;(391 Suppl):S362-9.

3. Davatchi F, Abdollahi BS, Mohyeddin M, Shahram F, Nikbin B. Mesenchymal stem cell therapy for knee osteoarthritis: preliminary report of four patients. Int J Rheum Dis. 2011; 14:211-5.

4. Somoza RA, Welter JF, Correa D, Caplan AI. Chondrogenic differentiation of mesenchymal stem cells: challenges and unfulfilled expectations. Tissue Eng Part B Rev. 2014;20:596608.

5. Pittenger MF, Mackay AM, Beck SC, Jaiswal RK, Douglas R, Mosca JD, Moorman MA, Simonetti DW, Craig S, Marshak DR. Multilineage potential of adult human mesenchymal stem cells. Science. 1999;284:143-7.

6. Mizuno H, Tobita M, Uysal AC. Concise review: adiposederived stem cells as a novel tool for future regenerative medicine. Stem Cells. 2012;30:804-10.

7. Freitag J, Ford J, Bates D, Boyd R, Hahne A, Wang Y, Cicuttini F, Huguenin L, Norsworthy C, Shah K. Adipose derived mesenchymal stem cell therapy in the treatment of isolated knee chondral lesions: design of a randomised controlled pilot study comparing arthroscopic microfracture versus arthroscopic microfracture combined with postoperative mes- 
enchymal stem cell injections. BMJ Open. 2015;5:e009332.

8. Koh YG, Kwon OR, Kim YS, Choi YJ, Tak DH. Adiposederived mesenchymal stem cells with microfracture versus microfracture alone: 2-year follow-up of a prospective randomized trial. Arthroscopy. 2016;32:97-109.

9. Bansal H, Comella K, Leon J, Verma P, Agrawal D, Koka P, Ichim T. Intra-articular injection in the knee of adipose derived stromal cells (stromal vascular fraction) and platelet rich plasma for osteoarthritis. J Transl Med. 2017;15:141.

10. Frisbie DD, Kisiday JD, Kawcak CE, Werpy NM, Mcllwraith $\mathrm{CW}$. Evaluation of adipose-derived stromal vascular fraction or bone marrow-derived mesenchymal stem cells for treatment of osteoarthritis. J Orthop Res. 2009;27:1675-80.

11. Afizah $\mathrm{H}, \mathrm{Hui} \mathrm{JH}$. Mesenchymal stem cell therapy for osteoarthritis. J Clin Orthop Trauma. 2016;7:177-82.

12. Yubo M, Yanyan L, Li L, Tao S, Bo L, Lin C. Clinical efficacy and safety of mesenchymal stem cell transplantation for osteoarthritis treatment: a meta-analysis. PLoS One. 2017;12: e0175449.

13. Peterfy CG, Guermazi A, Zaim S, Tirman PF, Miaux Y, White D, Kothari M, Lu Y, Fye K, Zhao S, Genant HK. Whole-Organ Magnetic Resonance Imaging Score (WORMS) of the knee in osteoarthritis. Osteoarthritis Cartilage. 2004;12:177-90.

14. Orozco L, Munar A, Soler R, Alberca M, Soler F, Huguet M, Sentis J, Sanchez A, Garcia-Sancho J. Treatment of knee osteoarthritis with autologous mesenchymal stem cells: a pilot study. Transplantation. 2013;95:1535-41.

15. Wong KL, Lee KB, Tai BC, Law P, Lee EH, Hui JH. Injectable cultured bone marrow-derived mesenchymal stem cells in varus knees with cartilage defects undergoing high tibial osteotomy: a prospective, randomized controlled clinical trial with 2 years' follow-up. Arthroscopy. 2013;29:2020-8.

16. Vangsness CT Jr, Farr J 2nd, Boyd J, Dellaero DT, Mills CR, LeRoux-Williams M. Adult human mesenchymal stem cells delivered via intra-articular injection to the knee following partial medial meniscectomy: a randomized, double-blind, controlled study. J Bone Joint Surg Am. 2014;96:90-8.

17. Davatchi F, Sadeghi Abdollahi B, Mohyeddin M, Nikbin B. Mesenchymal stem cell therapy for knee osteoarthritis: 5 years follow-up of three patients. Int J Rheum Dis. 2016;19: 219-25.

18. Emadedin M, Ghorbani Liastani M, Fazeli R, Mohseni F, Moghadasali R, Mardpour S, Hosseini SE, Niknejadi M, Moeininia F, Aghahossein Fanni A, Baghban Eslaminejhad R, Vosough Dizaji A, Labibzadeh N, Mirazimi Bafghi A,
Baharvand H, Aghdami N. Long-term follow-up of intraarticular injection of autologous mesenchymal stem cells in patients with knee, ankle, or hip osteoarthritis. Arch Iran Med. 2015;18:336-44.

19. Gupta PK, Chullikana A, Rengasamy M, Shetty N, Pandey V, Agarwal V, Wagh SY, Vellotare PK, Damodaran D, Viswanathan P, Thej C, Balasubramanian S, Majumdar AS. Efficacy and safety of adult human bone marrow-derived, cultured, pooled, allogeneic mesenchymal stromal cells $\left(\right.$ Stempeucel ${ }^{\circledR}$ ): preclinical and clinical trial in osteoarthritis of the knee joint. Arthritis Res Ther. 2016;18:301.

20. Lamo-Espinosa JM, Mora G, Blanco JF, Granero-Molto F, Nunez-Cordoba JM, Sanchez-Echenique C, Bondía JM, Aquerreta JD, Andreu EJ, Ornilla E, Villaron EM, ValentiAzcarate A, Sanchez-Guijo F, Del Canizo MC, Valenti-Nin JR, Prosper F. Intra-articular injection of two different doses of autologous bone marrow mesenchymal stem cells versus hyaluronic acid in the treatment of knee osteoarthritis: multicenter randomized controlled clinical trial (phase I/II). J Transl Med. 2016;14:246.

21. Orozco L, Munar A, Soler R, Alberca M, Soler F, Huguet M, Sentis J, Sanchez A, Garcia-Sancho J. Treatment of knee osteoarthritis with autologous mesenchymal stem cells: twoyear follow-up results. Transplantation. 2014;97:e66-8.

22. Vega A, Martin-Ferrero MA, Del Canto F, Alberca M, García V, Munar A, Orozco L, Soler R, Fuertes JJ, Huguet M, Sanchez A, Garcia-Sancho J. Treatment of knee osteoarthritis with allogeneic bone marrow mesenchymal stem cells: a randomized controlled trial. Transplantation. 2015;99:168190.

23. Martin I, Baldomero H, Bocelli-Tyndall C, Passweg J, Saris D, Tyndall A. The survey on cellular and engineered tissue therapies in Europe in 2010. Tissue Eng Part A. 2012;18:2268-79.

24. Simmons PJ, Torok-Storb B. Identification of stromal cell precursors in human bone marrow by a novel monoclonal antibody, STRO-1. Blood. 1991;78:55-62.

25. Skowronski J, Rutka M. Osteochondral lesions of the knee reconstructed with mesenchymal stem cells: results. Ortop Traumatol Rehabil. 2013;15:195-204.

26. de Windt TS, Hendriks JA, Zhao X, Vonk LA, Creemers LB, Dhert WJ, Randolph MA, Saris DB. Concise review: unraveling stem cell cocultures in regenerative medicine: which cell interactions steer cartilage regeneration and how? Stem Cells Transl Med. 2014;3:723-33.

27. Agung M, Ochi M, Yanada S, Adachi N, Izuta Y, Yamasaki T, Toda K. Mobilization of bone marrow-derived mesen- 
chymal stem cells into the injured tissues after intraarticular injection and their contribution to tissue regeneration. Knee Surg Sports Traumatol Arthrosc. 2006;14:1307-14.

28. Dominici M, Le Blanc K, Mueller I, Slaper-Cortenbach I, Marini F, Krause D, Deans R, Keating A, Prockop Dj, Horwitz E. Minimal criteria for defining multipotent mesen- chymal stromal cells: the International Society for Cellular Therapy position statement. Cytotherapy. 2006;8:315-7.

29. Xia P, Wang X, Lin Q, Li X. Efficacy of mesenchymal stem cells injection for the management of knee osteoarthritis: a systematic review and meta-analysis. Int Orthop. 2015;39: 2363-72. 